Binghamton University

The Open Repository @ Binghamton (The ORB)

Public Administration Faculty Scholarship

Public Administration

2-1-2016

\title{
Program Performance and Multiple Constituency Theory
}

David Campbell

Binghamton University, dcamp@binghamton.edu

Kristina T. Lambright

Binghamton University--SUNY, klambrig@binghamton.edu

Follow this and additional works at: https://orb.binghamton.edu/public_admin_fac

Part of the Public Administration Commons

\section{Recommended Citation}

Campbell, David and Lambright, Kristina T., "Program Performance and Multiple Constituency Theory" (2016). Public Administration Faculty Scholarship. 54.

https://orb.binghamton.edu/public_admin_fac/54

This Article is brought to you for free and open access by the Public Administration at The Open Repository @ Binghamton (The ORB). It has been accepted for inclusion in Public Administration Faculty Scholarship by an authorized administrator of The Open Repository @ Binghamton (The ORB). For more information, please contact ORB@binghamton.edu. 
Program Performance and Multiple Constituency Theory

David A. Campbell*

Associate Professor

Department of Public Administration

College of Community and Public Affairs

Binghamton University

Post Office Box 6000

Binghamton, NY 13902-6000

6077779181

dcamp@binghamton.edu

Kristina T. Lambright

Associate Professor

Department of Public Administration

College of Community and Public Affairs

Binghamton University

Post Office Box 6000

Binghamton, NY 13902-6000

6077779186

klambrig@binghamton.edu

*Corresponding author

Key Words: Accountability, Performance Measurement, Effectiveness, Nonprofit-Funder

Relations 
Abstract: This paper seeks to deepen our understanding of performance measurement in the nonprofit human services sector by investigating issues related to funder and provider motivations for collecting and analyzing program level performance information. Using survey and interview data from nonprofit human service organizations and their funders (nonprofit and local government), we analyze this study's research questions through the lens of multiple constituency theory. Consistent with multiple constituency theory, the study found similarities and differences in funder and provider motivations for collecting performance information. The study also indicates other key constituents (such as service beneficiaries, donors to nonprofit organizations and other levels of government that provide resources to local governments) play a role in defining program performance. The paper suggests that multiple constituency theory applies to program level performance and that understanding program performance requires considering the perspectives of multiple stakeholders. 


\section{INTRODUCTION}

People pursue public service to have a meaningful impact on the issues they care about most, and determining how to assess the impact they have has become a source of vigorous debate. This debate has raised a variety of important questions. What information is most useful in determining whether an organization's work has made a positive contribution to a community? Why do we want to learn about performance? Is it to improve practice? Is it to make the case that an organization deserves additional resources? Or, is it something else? How do we define performance and who defines it?

Leaders of nonprofit human service organizations collect and analyze a wide range of information to learn about their programs' performance. This information can take the form of program evaluations, outcome measurement, satisfaction surveys or other tools, often collected as a requirement by funders, though sometimes initiated by the provider. This paper seeks to deepen our understanding of how funders and providers in the nonprofit human services sector approach program performance measurement. We investigate the type of data they collect, their motivations for collecting these data, the similarities or differences in their approaches, whether they have a shared understanding of what constitutes program performance, and the potential for funders and providers to collaborate in the performance measurement process. Our approach is a system-level rather than organization-level analysis. That is, we look at performance measurement practices of funders and providers in general rather than conducting an individual analysis of each organization's performance measurement choices.

This study's focus on program performance and the questions it addresses is similar to those raised by researchers studying organizational effectiveness, particularly those who have 
used multiple constituency theory to define and increase our understanding of that issue. We believe that multiple constituency theory not only explains how stakeholders understand organizational effectiveness but also program performance. The potential for extending multiple constituency theory in this way is important because organizational effectiveness and program performance are different constructs. In fact, Herman \& Renz in their culminating work on organizational effectiveness, (2008) make a strong case for this distinction as one of their nine theses and find support for it in other researchers' work. In simple terms, organizational effectiveness is not an aggregation of program outcomes or other program performance measures; rather it encompasses program performance as well as other aspects of management and governance that program performance typically does not address such as board performance. For purposes of this paper, program performance measurement practices refer to the general approach organizations take to assess the performance of their programmatic activities. Examples of program performance indicators include outcome achievement and participant satisfaction.

Applying multiple constituency theory in this way also has the potential to contribute new knowledge about practice. Because of resource dependencies, reporting obligations developed by funders play a large role in defining performance and determining the measures providers use. As Ebrahim (2005) has argued, this dynamic tends to exclude provider and service recipients' perspectives on performance and de-emphasizes critical benefits of performance measurement, such as organizational learning. Other researchers have offered similar critiques of how funders approach performance measurement (Benjamin, 2012; Bonbright, Campbell \& Nguyen, 2009; Campbell, 2010); adopting a multiple constituency approach when assessing program performance has the potential to address those concerns. 
Acknowledging the power relationships that define performance measurement and the distinct perspectives of participants could lead to the development of more comprehensive and useful performance measurement processes. In the next section, we summarize multiple constituency theory and explain its relevance to program performance measurement. We follow with findings from survey and interview data and conclude by discussing our study's implications for theory, practice and future research. 


\section{MULTIPLE CONSTITUENCY THEORY}

Many researchers have examined nonprofit program performance, often framing their work in terms of accountability and related organizational theories. For example, scholars drawing on agency theory explain performance by evaluating the extent to which agents have expectations set by funders, as principals (Benjamin, 2010; Lambright, 2009; Van Slyke, 2007).

Researchers have also used resource dependence theory as lens for understanding how leaders of human service organizations approach program performance. Like agency theory, resource dependence focuses on the relationship between funders and providers. According to this perspective, providers' resource dependence creates an asymmetrical power relationship, enabling funders to dictate the performance information providers collect (Carman, 2011; Ebrahim, 2005; Froelich, 1999; Mayhew, 2012). Researchers have also used institutional theory to explain performance measurement practices, emphasizing how external forces affect organizational legitimization strategies (Carman, 2011; DiMaggio \& Powell, 1983; Ebrahim, 2005).

While many nonprofit scholars have made a persuasive case for the role agency, resource dependence and institutional theories play in explaining performance measurement practices, some of those scholars (and others) have provided compelling critiques that these theories do not provide a complete explanation of the performance measurement process in nonprofit organizations (see, for example, Benjamin, 2008, 2012; Benjamin \& Campbell, 2014; Ebrahim, 2005, 2010). Each critique raises distinct issues, but they share a concern that these theories do not account for the multiple stakeholders who influence the performance measurement process in nonprofit organizations. These critics contend that agency, resource dependence and institutional theories explain performance measurement primarily in terms of measures imposed 
on providers by funders. In this way, the theories do not consider the perspectives of providers, let alone other important constituents, notably service beneficiaries, but also volunteers, nonprofit organization staff and other community members. Limiting our understanding of what constitutes performance to funder defined measures is problematic for several reasons. As Ebrahim $(2005,2010)$ notes, this approach emphasizes outcomes at the expense of learning from performance results. In addition, it limits service beneficiaries' (and others') opportunities to shape the work of nonprofit organizations and define what constitutes success. Finally, it may prevent nonprofit leaders from gathering critical information from beneficiaries that these leaders can then use to influence decisions made by policy makers and other powerful community institutions. As a result, nonprofit organizations may be unable to play an essential mediating role, between constituents and those institutions (Guo, 2007).

One way to address these critiques is to revisit multiple constituency theory-developed thirty years ago to help us understand organizational effectiveness - as a complement to these other theoretical perspectives. Measuring organizational effectiveness presents a wide range of challenges. Herman \& Renz $(1997,1999,2004,2008)$ have chronicled many of these issues and contributed significantly to our understanding of nonprofit effectiveness. They note that measuring nonprofit effectiveness is difficult because of the lack of comparability, the absence of agreed upon standards and concerns regarding whether reviewers' assessments of organizations are consistent. Cameron (1986, p. 542) identifies seven different approaches scholars have developed to measure effectiveness in organizations, including goal attainment (effectiveness is achieving established goals); systems resource (effectiveness is securing resources); and faultdriven (effectiveness is avoiding faults). Goal attainment is the most dominant among these 
approaches and helps us to understand why multiple constituency theory emerged as an alternative.

The authors of multiple constituency theory argue that measuring effectiveness in terms of goal attainment assumes "that it is possible, and desirable to arrive at a single set of evaluative criteria, and thus at a single statement of organizational effectiveness" (Connolly, Conlon \& Deutsch, 1980, p. 212). In contesting that approach, they emphasize first that organizations are composed of multiple subgroups, each with its own set of interests, and second that organizations have a diverse set of external stakeholders, each with distinct concerns (Balser \& McClusky, 2005; Herman \& Renz, 1997, 2008; Zammuto, 1984). If we accept this definition of organizations, the notion of a "single statement of organizational effectiveness" is implausible; different subgroups and stakeholders will not be able to come to consensus about what constitutes effectiveness and will define effectiveness differently based on their distinct perspectives. In short, multiple constituency theorists retain a positivist, goal attainment perspective, but emphasize that different constituents pursue different goals (Herman \& Renz, 1997).

Several researchers have advocated for a multiple constituency view of effectiveness (Connolly, et al, 1980; Ebrahim, 2005; Herman \& Renz, 2008; Zammuto, 1984), and empirical research indicates that constituent groups have distinct definitions of both overall organizational effectiveness (Addicott \& Ferlie, 2006; Andrews, Boyne \& Walker, 2006; Balser \& McCloskey, 2005; Boschken, 1994; Herman \& Renz, 1997; Jun \& Shiau, 2012) and the effectiveness of specific functions within organizations, such as human resources management (Tsui, 1990). Similarly, Ebrahim $(2003,2005,2010)$ in a considerable body of work on this topic, indicates that staff of nonprofit organizations have multiple constituents, each of whom represent 
competing accountabilities. He identifies three levels of accountability: upward, lateral and downward. Each level of accountability focuses on different stakeholder groups. Upward accountability is generally to funders; lateral is to other staff within the organization; downward is to service beneficiaries, volunteers and other community stakeholders.

One indicator of multiple constituency theory's power is the contrast it provides with organizational theories that emphasize funder defined perspectives on performance. A multiple constituency perspective suggests that leaders have the option to use input and perspectives on performance from a variety of constituents and may not define performance solely based on funder preferences. Zammuto (1984) argues that how an organization's leaders choose to define effectiveness reflects whose perspectives dominate the organization. He notes "organizational effectiveness is fundamentally a values-based concept in that the whole of the evaluation process requires the application of value judgments from the selection of constituencies and the weighting of their judgments to the development of recommendations for future organizational performance" (p. 614).

Traditionally, researchers have used multiple constituency theory to understand organizational effectiveness; however, it may also explain program performance. Programs within nonprofit organizations have many constituents, including program participants, staff, funders, peer agencies the general public and government representatives (Balser \& McClusky, 2005; Herman \& Renz, 1997; Jun \& Shiau, 2012). Each group is likely to have its own perspective on program goals and performance. This study applies multiple constituency theory to understand the performance assessment goals of not only nonprofit funders but nonprofit providers as well. 


\section{RESEARCH DESIGN}

To address the study's research questions, we surveyed and interviewed representatives of funder and provider organizations in a six-county area in South Central New York. The county populations ranged from approximately 50,000 to 200,000. For the purposes of data collection, we defined performance information as any data providers collect regarding their clients or constituents in order to learn about their experiences. Examples of performance information include: outcome measurements, satisfaction surveys, goal accomplishments, and output data.

Sample. To develop the sampling frame, we contacted all local United Way chapters and major local private foundations funding human service nonprofits in the region. We also contacted all county departments in the region involved in the delivery of human services including: departments of health, mental health, social services, youth services and aging. We asked each funder organization for: (1) the names and email addresses of all the staff in their organization who supervise grants and/or contracts and (2) the names of the nonprofit agencies that their organization currently funds. We also conducted web searches, used information from a local trade association, contacted providers directly, and, when possible, identified the email addresses of other administrators involved in the performance management process. The majority of providers received funding from multiple funders in our sample.

The Survey. In the first phase of our study, we emailed separate electronic surveys to all funders and providers in our sample. We sent links for our surveys to 35 individuals working for county government, 13 individuals working for a public charity (i.e. a community foundation or a United Way), 17 individuals working for a private foundation, and 192 individuals working for provider organizations. In order to increase the response rate, we made follow-up calls to funders 
and providers in our sample encouraging them to complete the survey. We received 48 usable funder surveys and 109 usable provider surveys, representing a 74\% response rate and a 57\% response rate, respectively. The vast majority of respondents skipped very few, if any, survey questions. Of the completed funder surveys, there were 23 respondents who worked for county government, 14 who worked for a public charity and 11 who worked for a private foundation.

Before completing the surveys, we assured participants that their responses would be confidential. The two surveys contained primarily close-ended questions. Most questions appeared on both surveys with slight wording modifications. For example, we asked funders about the performance information their organizations receive while we asked providers about the performance information their organizations collect. We began by asking all respondents for basic organizational information, including the type of performance information that is collected. On the remainder of the survey, we asked respondents questions about their experiences with performance measurement. This latter set of questions asked respondents to indicate their level of agreement with a series of statements using a five-point Likert scale where 1 equals strongly disagree and 5 equals strongly agree. We used this scale to assess respondents' performance measurement goals because we were interested in exploring the extent to which respondents prioritized different goals. This survey was part of a larger study. Appendices 1 and 2 include all questions from the funder survey that are relevant to this paper as well as two relevant questions from the provider survey that were not asked on the funder survey. The complete funder and provider surveys are available upon request. The survey questions were developed based on survey and focus group data collected by one of the authors in a prior study (Bonbright, et al., 2009). To make sure the survey instruments were clear, local nonprofit leaders reviewed the instruments and gave us feedback that we used to improve them. 
We excluded from our analysis the four providers who indicated that their organizations did not collect performance information and the three funders who indicated that their organization did not receive performance information. We calculated descriptive statistics and used the Mann-Whitney test to assess the statistical significance of differences between funders' and providers' performance measurement goals. The Mann-Whitney test assesses the null hypothesis that there is no difference between two samples. The Mann-Whitney test is appropriate for ordinal data, and researchers use it in place of a two sample t-test when data do not have normal distributions, which was the case with much of our data. This test allowed us to identify any statistically significant differences in the extent to which funders and providers agreed with various performance measurement goals. We then compared these results with our interview results to see if our survey and interview findings were consistent.

Interviews. In the second phase of our study, we randomly selected twenty funders and twenty providers from our sample for follow-up interviews. We divided the funders into three groups: county government departments, public charities, and private foundations. Of the twenty funder interviews, ten came from county government, five from public charities and five from private foundations. The purpose of these semi-structured interviews was to explore the preliminary findings of our survey in greater depth. We chose to do interviews because the potential for social desirability bias in our survey results concerned us, especially given the relatively high average Likert ratings that many of the performance measurement goals received from survey respondents. The interviews also allowed us to verify that the statistical differences between funders' and providers' performance measurement goals identified as part of our quantitative analysis were meaningful to the practitioners we interviewed. Another advantage of 
the interviews was that they enabled us to identify performance measurement goals that we had not included on the survey.

Like the survey, the interviews were part of a larger study. Relevant to this paper, we asked interviewees open-ended questions about: the types of performance information that were collected, their goals in collecting it; the role service beneficiaries play in the performance assessment process; and collaboration between funders and providers with performance measurement. We also asked them to provide information about their organization's budget, staffing and service area(s).

At the beginning of each interview, we guaranteed confidentiality. Average interview length was forty-five minutes. All interviews were recorded, transcribed, and coded. Initial codes were developed based on the funder and provider survey instruments and on past research one of the authors had conducted. This list of codes was then revised and augmented through an inductive process based on analysis of the interview transcripts. Pattern-matching (for a description see Yin, 2013) was also used as part of the data analysis. 


\section{FINDINGS}

Our findings indicate funders and providers approach the performance measurement process differently. We begin describing by the funders' approach using the survey and interview data we collected. Next we summarize our results for the providers. Finally, we compare the results for both groups, highlighting similarities and differences in their approaches.

Performance Information Required by Funders. The survey and interview results about the type of data funders commonly required were similar. Both indicated that outcome data were an important source of performance information for funders. Table 1 summarizes survey and interview data on the percentage of funders requesting various forms of performance information. As Table 1 notes, $89 \%$ of respondents on the funder survey and $80 \%$ of respondents in the funder interviews required providers to report outcome data. Survey and interview data also indicate that funders frequently required providers to report information funders could use to verify providers' activities including expenditure data and information on outputs.

<Insert Table 1 about here.>

Far fewer funders asked providers to conduct satisfaction surveys. Only $40 \%$ of funders indicated on the survey that they required providers to report satisfaction surveys, and respondents in only $10 \%$ of the funder interviews ( 2 interviews) reported collecting data on client satisfaction.

Funder Motivations for Collecting Performance Information. As indicated in Table 2, both the survey and interview data suggest that key reasons funders collect performance information include to identify outcomes, verify that the funded work has been done, and learn about community needs. Table 2 summarizes the reasons funders and providers collect 
performance information. The second and third columns of Table 2 indicate the number of funder and provider interviews in which respondents reported a particular motivation for collecting performance information. The fourth and fifth columns of Table 2 report the average Likert scale ratings funders and providers gave the various reasons on the surveys.

<Insert Table 2 about here.>

Consistent with our finding that outcome data are often required by funders, one of the most important reasons funders identified for collecting performance information was to demonstrate provider outcomes. This was the reason most commonly identified by interviewees and it received the highest mean score on the funder survey. One county employee's comments were representative: "We have to make decisions on funding, and the emphasis on outcomes... is important the last few years. It's critical to see the outcomes."

Many funders also reported that verifying providers had completed work was a key motivator in collecting performance information: respondents in eleven funder interviews cited verification as a reason for collecting performance data, and this goal received the second highest mean score on the funder survey. Comments like this one by a county employee were typical: "I want to learn are they [the providers] doing what we ask them to do. Are they seeing the number of clients we agreed to? If not, why not?"

Another key reason why funders collected performance information as indicated by both the survey and interview data was to learn about community needs; ten interviewees identified this motivation. According to one:

It [the data collected] also gives us feedback on the community itself indirectly. If there's a failure for a program to work or for funding to emerge what does that tell us about the community as a whole. Depending on the pattern from grantees you may get to see something emerging. 
The emphasis on learning about community needs is a perspective that is consistent with the nature of funders' work. Institutional funders by definition support an issue area and/or community. For that reason, learning about community needs helps funders perform their roles more effectively.

In addition, funders collected performance information to help inform future funding decisions, with respondents in ten funder interviews citing this reason. For example, one funder commented: "We could not make these [funding] decisions without the feedback and data. We would have nothing to base it on. You get questions all the time especially when it comes to funding. We have to back it with something." Further, nearly three-quarters of the funders in our survey agreed that the performance information their organization receives from funded agencies affects subsequent funding decisions.

Finally, many funders collected performance information to meet their funders' requirements: respondents in eight funder interviews collected performance information in order to demonstrate accountability to the individuals and institutions from which they derive their grantmaking or contracting resources. County funders emphasized the importance of meeting their obligations to the state and federal government while private funders focused on accountability to their donors.

We also analyzed whether the three types of funder organizations included in our study (private foundations, public charities and county government departments) had different motivations for collecting performance information. These results are summarized in Table 3. As shown in Table 3, all funder groups emphasized some of the same goals for collecting performance information such as to identify outcomes and verify that the funded work had been done. However, there were also important differences in motivations. For instance, while 
meeting funder requirements was a key concern for three of the five public charities and five of the ten county funders, none of the private foundation interviewees identified this goal. In addition, respondents in more than half of the interviews with counties and public charities indicated performance data had affected subsequent funding decisions but only one private foundation mentioned using performance data in this way. Finally, four of the ten county interviewees reported requesting performance data to better understand client needs; by contrast, only one private funder reported using performance data to achieve this goal.

<Insert Table 3 about here.>

Funder Views on Collaboration in the Performance Measurement Process. Many

funders highlighted the importance of collaboration between funders and providers in the performance measurement process. Respondents in eight funder interviews, including those from two counties, three public charities and three private foundations, wanted the performance measurement process to be more collaborative. They viewed the performance measurement process as a partnership and used it to cultivate relationships with the agencies they funded. One county employee described, "Typically in this community we work together well. Our providers want our business, and we need them too. It's not adversarial; our goals may be unrealistic to them so we can try to adjust." Two of these funders commented that their organizations have tried to de-emphasize performance measurement practices providers may perceive as punitive in an effort to build stronger relationships with the agencies they fund. According to one:

We're trying to get away from feedback being viewed as a measure for punitive action or some kind of determination on whether or not we fund them again. We're trying to move beyond that to: 'We want you to be successful. It does no one good if you're not successful and how can we create this partnership where we can learn from our shared experiences.' 
Another two funders noted that fostering strong relationships with providers can reduce the need for formalized performance data. One commented that by relationship building "you're overriding a need for carefully crafted, printed data reports."

Consistent with this collaborative view, respondents in five of the funder interviews indicated that they used the performance measurement process to collect information to determine whether a funded organization needed technical assistance to implement the grant/contract. For example, one county social services manager reported asking the following questions when reviewing provider performance reports: "Is it [the performance information] what we're asking for? If not, we want to talk it over. Are they meeting outcomes according to the contract? What do they need from us? Is the program at capacity? How is the budget?" Although respondents in several funder interviews emphasized a desire to have collaborative performance measurement processes, the results of the funders' survey suggest room for improvement: less than half of the respondents were satisfied with the extent to which the agencies their organization funded participated in the performance measurement process.

Additional Performance Information Collected by Providers. To supplement our data on funders, we collected information about providers' practices and views as well. Table 4 summarizes survey data on the additional performance information that providers most commonly collected on their own, for funders other than county or local private ones, or for accreditation purposes. Much of the additional data that providers collected involved learning more about clients' experiences. According to Table 4, satisfaction surveys are the most common type of additional performance information that providers collected: two-thirds of respondents to the provider survey indicated their organization conducts satisfaction surveys. Providers also often conducted client interviews and collected quality assurance information, 
even though neither county nor private funders required it. In addition, more than $40 \%$ of respondents collected additional information on expenditures, outcomes, goal accomplishments and outputs.

<Insert Table 4 about here.>

Provider Motivations for Collecting Performance Information. The two reasons for collecting performance information most important to providers were to improve service and to respond to client needs. These findings reflect the emphasis providers place on their relationships with clients. Table 2 indicates service improvement received the highest average rating from providers on the survey. In addition, service improvement was the reason most commonly cited in the provider interviews. As one provider described:

We want to do a better job and have feedback on what we think and do. I think it's a continuous improvement cycle. We want to know whether or not the programs we're running are efficient and effective. If not, we either want to terminate them or change them so they are relevant and helpful to people.

Responsiveness to client needs received the second highest average rating from providers on the survey and was cited as a reason for collecting performance information in half of the provider interviews. Many providers collected performance information to learn about clients' experiences and unmet needs. One indicated:

We are trying to work towards community integration and make sure it's a person centered type of approach, not just squeezing somebody into a program but trying to adapt what we provide to the needs of the individual in that family. Those are the things we try to find out. Are we living up to expectations?

The emphasis that providers place on collecting performance information to improve service and meet client needs reflects providers' view that clients are one of their core constituencies. 
While not asked on the survey, respondents in nine provider interviews indicated that

another important motivation for collecting performance information was for organization level or program specific planning. As one provider indicated:

We do use it [performance data] for program planning. If we see a trend where kids are struggling in certain areas then we know what to target. For example, the one year we saw a lot of issues with internet safety, Facebook, kids giving out way too much information. We had a gathering, we try to do something fun and educational. We had someone speak about how to look at items on the computer to talk to the girls about too much information. We try to use it for driving program activities.

An additional reason many indicated they collected performance information was to meet funder requirements, with respondents in eight interviews mentioning this motivation. For example, when asked the reasons why his organization collected performance data, one provider responded: "The first is compliance with the funding source. That's the biggest driver because it's, 'Here's the money. We need you to measure some things.' In essence we want to maintain compliance with the contracts we have." Although the desire to meet funder requirements was mentioned in many provider interviews, this motivation received the lowest average rating from providers on the survey. The reason for the discrepancy between the survey and interview results is unclear.

Provider Views on Collaboration in the Performance Measurement Process. Providers described mixed experiences collaborating with funders. Respondents in sixteen provider interviews indicated they had successfully collaborated with at least one major funder in the performance measurement process. Providers reported collaborative relationships with a wide range of funders including counties, state agencies, local United Way chapters and private foundations. At the same time, respondents in thirteen interviews identified instances in which funders did not want their input in the performance measurement process. Consistent with these mixed experiences, $58 \%$ of providers were satisfied with the collaborations they had with county 
funders in the performance measurement process, and 55\% were satisfied with the collaborations they had with local private funders.

The extent of the collaborations between providers and funders also varied. Some were modest. For instance, one provider indicated that a funder limited collaboration to asking how the performance measurement aspect of its proposal development process could be improved. In other cases, the collaborations were more extensive. One provider commented, "Most of our contact is with State Agency X. I've found them to be wonderful. We have an excellent working relationship; we get technical assistance we need. I've invited the director to come here for a statewide initiative. He was responsive. I've been to their national conference. I think it's wonderful. They do a good job."

Comparison of Funders' and Providers' Approaches. There are both similarities and differences in how funders and providers approach the performance measurement process as summarized by Table 5. Each group values information on expenditures, outcomes and outputs with funders frequently requiring providers to collect this information and providers often collecting this information even when it is not required by county or local private funders. By contrast, providers are also interested in receiving more direct feedback from clients such as satisfaction data. Reflecting the emphasis providers placed on their relationships with clients, providers' top reasons for collecting feedback were to improve service and meet client needs. In contrast, funders reported outcomes and verification as their most important reasons. We used Mann Whitney tests to explore whether the differences in the two groups' priorities were significant. These results are detailed in Table 6 . Funders who completed the survey were significantly more likely than providers to agree that verification was one of their performance measurement goals, and providers were significantly more likely than funders to agree service 
improvement and client responsiveness were performance measurement goals. Some of the key stakeholder groups for funders and providers in the performance measurement process were also different. Providers collected performance information to respond to the interests of funders and service beneficiaries. Funders pursued performance measurement practices that reflected their accountability to stakeholders from which they receive resources (individual donors, the state and federal government, etc.). While funders and providers differed in their performance measurement priorities and some of their primary stakeholders, many funding relationships still involved collaborative performance measurement processes. At the same time, responses from both funders and providers suggest that there is room for improvement in this area.

<Insert Tables 5 and 6 about here.> 


\section{IMPLICATIONS FOR THEORY}

This study examined motivations for collecting performance information among human service funders and providers. Consistent with multiple constituency theory, we found differences in the two groups' motivations and the stakeholders they identified as critical in defining performance. Collectively, their experience indicates that multiple constituents have a stake in performance measurement and is consistent with research indicating that complex accountability structures shape performance assessment in nonprofit organizations. Utilizing Ebrahim's (2010, p. 102) framework, this study found both “downward” accountability (for providers) and "upward" accountability (not only for providers, but for certain funders as well). This framework views accountability as relational and supports the idea that assessing performance involves learning the perspective of multiple constituents. Our findings also align with research by Knutsen \& Brower (2010, p. 588) who argue that providers' accountability to different stakeholders generate distinct assessments of performance. For example, they identify both "instrumental" and "expressive" accountability structures, the former largely reflecting providers' accountability to funders (but also to beneficiaries and staff), the latter, emphasizing accountability to the community, mission and beneficiaries.

In addition, our findings are consistent with previous research (Bonbright et al, 2009; Campbell, Lambright \& Bronstein, 2012) that providers and funders have different motivations for collecting performance information. These contrasting priorities reflect each group's distinct interests and attention to different constituents. Funders collect performance information to learn whether their expectations for the resources they provided were met, as well as to gather planning information consistent with their mission. Providers, by contrast, emphasized 
collecting performance information to enhance their responsiveness to clients and improve services.

These competing perspectives raise important questions about current approaches to performance measurement. Ebrahim (2005, p. 56) argues against "myopia" in the accountability practices of human service nonprofit organizations. He suggests that funder driven emphases on outcome measurement may be too short-term in focus, punitive in nature, and de-emphasize organizational learning. The contrast in our findings between funders' prioritization of outcome measurement and providers' focus on service improvement is consistent with Ebrahim's concern. Our findings shed some light on these concerns, and we address them in our discussion of collaboration later in this paper.

Drawing on a range of organizational theories, such as resource dependence, institutionalism and agency theory, researchers often explain performance measurement performance measurement primarily in terms of measures imposed on providers by funders (Benjamin, 2010; Campbell, et al, 2012; Carman, 2011; Mayhew, 2012). While these theories are useful in explaining organizational behavior, they are incomplete. They tell much of the story about why and how performance measurement takes place in nonprofit human services. The findings of this study, however, suggest that incorporating a multiple constituency perspective would account for additional stakeholders shaping performance measurement, particularly in human service organizations, where beneficiary engagement is an essential aspect of organizational practice. In such settings, adopting a multiple constituency approach would provide a more comprehensive view of what constitutes program performance.

One can argue, for example, that funders' emphasis on outcome measurement, is too limiting. In assessing program performance, outcome measurement may be the functional 
equivalent of the goal attainment approach to measuring organizational effectiveness, "a single set of evaluative criteria" that captures what constitutes performance (Connolly, 1980, p. 212). Given the number of stakeholders in the performance assessment process, coming to consensus on a single measure of program performance is likely to be difficult if not impossible for most organizations. The finding that funders and providers have different purposes for collecting performance information, which reflect their different primary interests, supports this claim.

The challenge of adopting a multiple constituency approach to program performance measurement is that current practices privilege the perspective of funders over others. For example, providers emphasized the importance of responsiveness to funders; yet funders did not consistently seek the kind of information providers valued. Funders required outcome information while providers valued information that told them about beneficiary experiences (such as satisfaction data). Carman's (2009) work reflects this dilemma, too. While she found that the type of performance information funders required of providers varied, funders nonetheless dictated the performance information providers collected. If providers are dependent on funders and funders do not ask for input from service beneficiaries (through mechanisms such as satisfaction surveys), then the funder-defined perspective on performance may crowd out the perspective of other constituents. To address this concern, we can draw on Zammuto's (1984, p. 614) critique of organizational effectiveness, cited earlier. He describes organizational effectiveness as "a values-based concept...that requires the application of value judgments, from the selection of constituencies and the weighting of their judgments, to the development of recommendations for future organizational performance." This perspective is consistent with our findings and suggests implications for practice that can improve program performance measurement processes and bridge the divide among multiple constituents. 


\section{IMPLICATIONS FOR PRACTICE}

A more effective performance measurement process would involve collaboration and negotiation among multiple constituents in defining what constitutes performance and how to measure it. Our findings suggest funders and providers are open to moving in this direction. Funders acknowledge greater potential for collaboration with providers: respondents in eight of twenty funder interviews (admittedly, not even a majority), across all funder types, embraced a collaborative rather than adversarial relationship with providers in the performance assessment process. In addition, respondents in five interviews used performance information to guide their technical assistance efforts. Both practices could improve the performance measurement process and move beyond the "myopia" that Ebrahim (2005) argues against. In fact, this approach suggests a willingness by funders to use performance information as a way to encourage learning across provider groups and the potential for increased use of cluster evaluations as a performance measurement strategy. As a supplement to these general approaches, leaders in the performance measurement process, notably funders, but also providers, could develop practices that acknowledge that performance measurement involves multiple stakeholders.

One approach would be to view the performance measurement process as a negotiation among key stakeholders, certainly funders, providers and beneficiaries, if not others. Such a process would ask each stakeholder to identify what performance information each desires, the goals for collecting it and how each would use it. Participants would negotiate these questions and the resources needed to implement the performance measurement process. The success of this approach, however, would depend on participants' ability to overcome the asymmetrical power dynamics that have led to dissatisfaction with current practices. Indeed, the general lack of funder interest in downward accountability evidenced in this study raises challenges for this 
approach. To succeed, providers and beneficiaries may need to be more forceful advocates for an alternative view of performance. Scholars can advance this approach by acting as conveners in encouraging funders and all stakeholders in the performance measurement processes to reconsider current practices and pursue reforms.

\section{STRENGTHS AND LIMITATIONS}

This research design had important advantages. Our mixed methods approach enabled us to use qualitative data to enrich our understanding of the survey findings. Our ability to guarantee interviewee confidentiality may have made it easier for participants to discuss more sensitive issues. The research design had limitations as well. Our study focused on funders and providers in a six-county region that included small and medium-sized cities and the surrounding suburban and rural communities. While the research design captured providers' major sources of financial support, it does not include some minor funding sources, Community Development Block Grant (CDBG) funds (administered through cities in this region) chief among them. This region has also struggled economically. These limitations may affect the generalizability of our findings to larger counties and cities and regions with more robust economies. In addition, the relationships between funders and providers described in our study may not be representative of these relationships in more densely populated communities.

\section{FUTURE RESEARCH}

This study suggests several areas for future research. First, this paper addresses motivations for performance measurement and definitions of performance. As important, it would be useful to learn how funders and providers use performance information. For example, do the actual uses of performance information reflect the "myopia" Ebrahim (2005) warns against, emphasizing short-term outcomes over organizational learning? What are the 
consequences of performance measurement practices that privilege one stakeholder's perspective on performance over others? In addition, as noted, our findings identified that funders were dependent on the individual donors and institutions (state and federal government) that supplied their financial support. We would benefit from learning more about how those resource dependencies shape performance measurement practices. This study considers performance measurement at the system level, the motivations of human service funders and providers across a region. Future research should consider individual level analyses of performance measurement practices of funders and providers. Such an approach would give us a more nuanced understanding of each organization's constituents and how those constituents shape the performance measurement process. Finally, it would be useful to undertake a systematic review of the range of critiques scholars have made about current performance measurement practices and their implications for practice. What kinds of reforms do they suggest and what role can researchers play in advancing those reforms? 


\section{Appendix 1: Relevant Questions from the Funder Survey}

This survey defines "feedback" as any information your funded organizations collect regarding their clients or constituents in order to learn about their experiences.

1. Which types of feedback does your organization request from the agencies it funds? Please select all that apply.
a. Outcome measurement
b. Satisfaction surveys
c. Goal accomplishment
d. Expenditure reports
e. Outputs (how much of a service/activity a funded organization performed)
f. Other (please specify)
g. We do not request feedback.

On a scale of 1 to 5 , with one being strongly disagree and 5 being strongly agree, please indicate your level of agreement with the following statements.

2. We ask organizations which we fund to provide feedback so that we can verify that the organization has done the work paid for by the grant or contract.

3. We ask organizations which we fund to collect feedback so that we can identify outcomes or accomplishments resulting from the grant or contract.

4. We ask organizations which we fund to collect feedback so that they will use the information to make improvements in their services or organizations as a whole.

5. We ask organizations which we fund to provide feedback as a way to empower their clients/constituents to have a say in the work of their organization.

6. We ask organizations which we fund to provide feedback to ensure they are responsive to the experiences of their clients/constituents.

7. We ask organizations which we fund to provide feedback to communicate to the larger community what the funded project has taught us about community issues or problems.

8. We ask organizations which we fund to provide feedback to learn about community needs.

9. Feedback information we receive from the organizations we fund affects my organization's subsequent funding decisions.

10. We are satisfied with the extent to which organizations we fund participate in the feedback process. 
Note: On the surveys, we use the more generic term "feedback" but in the text we use the term performance information to be consistent with terminology used in the literature. 


\section{Appendix 2: Additional Relevant Questions from the Provider Survey (not asked on Funder Survey)}

1. Does your organization collect additional feedback on its own, for other funders or for accreditation purposes, separate from the requirements of funders indicated above [county and local private funders in South Central New York]? Please select all that apply.

a. My organization does not collect any additional types of feedback on its own, for other funders or for accreditation purposes

b. Outcome measurement

c. Satisfaction surveys

d. Goal accomplishments

e. Expenditures reports

f. Outputs (how much of a service/activity your agency did)

g. Quality assurance information

h. Focus groups with clients/constituents

i. Interviews with clients/constituents

On a scale of 1 to 5 , with one being strongly disagree and 5 being strongly agree, please indicate your level of agreement with the following statements.

2. We collect feedback because funders require it. 


\section{Biographical Information}

David Campbell (dcamp@binghamton.edu) is associate professor in the Department of Public Administration in the College of Community and Public Affairs of Binghamton University. His research focuses on performance measurement and constituent voice in the nonprofit sector. Recent work has also considered the emerging role of social media in the nonprofit sector and how we teach about philanthropy. He has published in a cross-section of public administration and nonprofit management journals.

Kristina Lambright (klambrig@binghamton.edu) is associate professor in the Department of Public Administration in the College of Community and Public Affairs at Binghamton University. Her research interests include organizational performance, service delivery structure and contracting. She has published in a cross section of public administration and nonprofit management journals. 


\section{Sources}

Addicott, R., \& Ferlie, E. (2006). A qualitative evaluation of public sector organizations: Assessing organizational performance in health care. In Boyne, G.A., Meier, K.J., O’Toole, L.J., \& Walker, R.M. (Eds.), Public service performance: Perspectives on measurement and management (pp.14-34). New York: Cambridge University Press.

Andrews, R., Boyne, G.A., \& Walker, R.M. (2006). Subjective and objective measures of organizational performance: An empirical exploration. In Boyne, G.A., Meier, K.J., O’Toole, L.J., \& Walker, R.M. (Eds.), Public service performance: Perspectives on measurement and management (pp.14-34). New York: Cambridge University Press.

Balser, D. \& McClusky, J. (2005). Managing stakeholder relationships and nonprofit organization effectiveness. Nonprofit Management and Leadership, 15(3), 295-315.

Benjamin, L. M. (2008). Account space: How accountability requirements shape nonprofit practice. Nonprofit and Voluntary Sector Quarterly, 37, 201-223.

Benjamin, L.M. (2010). Funders as principals: Performance measurement in philanthropic relationships. Nonprofit Management \& Leadership, 20, 383-403.

Benjamin, L.M. (2012). Nonprofit organizations and outcome measurement: From tracking program activities to focusing on front line work. American Journal of Evaluation, $33(3), 431-437$.

Benjamin, L.M., \& Campbell, D.C. (2014). Programs aren't everything. Stanford Social Innovation Review, 12(2), 42-47

Bonbright, D., Campbell, D., \& Nguyen, L. (2009). The $21^{\text {st }}$ century potential of constituency voice. Report prepared for Alliance for Children \& Families, United Neighborhood Centers of America, and Keystone Accountability.

Boschken, H.L. (1994). Organizational performance and multiple constituencies. Public Administration Review, 54, 308-312.

Cameron, K. (1986). Effectiveness as paradox: Consensus and conflict in conceptions of organizational effectiveness. Management Science, 32(5), 539-553.

Campbell, D. A. (2010). Is constituent feedback living up to its promise? Provider perceptions of feedback practices in nonprofit human service organizations. Families In Society: The Journal of Contemporary Social Services, 91, 313-320.

Campbell, D.A., Lambright, K.T., \& Bronstein, L.R. (2012). In the eyes of the beholders: Feedback motivations and practices among nonprofit providers and their funders. Public Performance and Management Review, 36, 7-30. 
Carman, J.G. (2009). Nonprofits, funders and evaluation: Accountability in action. American Review of Public Administration, 39(4), 374-390.

Carman, J.G. (2011). Understanding evaluation in nonprofit organizations. Public Performance and Management Review, 33, 350-377.

Connolly, T., Conlon, E.M, \& Deutsch, S.J. (1980). Organizational effectiveness: A multiple constituency approach. Academy of Management Review, 5, 211-218.

DiMaggio, P.J. \& Powell, W.W. (1983). The iron cage revisited: Institutional isomorphism and collective rationality in organizational fields. American Sociological Review, 48, 147160.

Ebrahim, A. (2003). Making sense of accountability: Conceptual perspectives for northern and southern nonprofits. Nonprofit Management \& Leadership, 14, 191-212.

Ebrahim, A. (2005). Accountability myopia: Losing sight of organizational learning. Nonprofit and Voluntary Sector Quarterly 34(1), 56-87

Ebrahim, A. (2010). The many faces of nonprofit accountability. In, D. Renz (Ed.), The handbook of nonprofit leadership and management ( $3^{\text {rd }}$ ed., pp. 110-121). San Francisco: Jossey-Bass.

Froelich, K.A. (1999). Diversification of revenue strategies: Evolving resource dependence in nonprofit organizations. Nonprofit and Voluntary Sector Quarterly, 28, 246-265.

Guo, C. (2007). When government becomes the principal philanthropist: The effectis of public funding on patterns of nonprofit governance. Public Administration Review, 67(3), 458473.

Herman, R.D. \& Renz, D.O. (1997). Multiple constituencies and the social construction of nonprofit organization effectiveness. Nonprofit and Voluntary Sector Quarterly, 26, 185206.

Herman, R. D., \& Renz, D.O. (1999). Theses on nonprofit organizational effectiveness. Nonprofit and Voluntary Sector Quarterly, 28, 107-126.

Herman, R.D., \& Renz, D.O. (2004). Doing things right: Effectiveness in local nonprofits, a panel study. Public Administration Review, 64, 694-704.

Herman, R. D., \& Renz, D.O. (2008). Advancing nonprofit organizational effectiveness research and theory: Nine theses. Nonprofit Management and Leadership, 18, 399-414. 
Jun, K.N, \& Shiau, E. (2012). How are we doing? A multiple constituency approach to civic association effectiveness. Nonprofit and Voluntary Sector Quarterly. 41(4), 632-655.

Knutsen, W. \& Brower, R. (2010). Managing expressive and instrumental accountabilities in nonprofit and voluntary organizations: A qualitative investigation. Nonprofit and Voluntary Sector Quarterly, (39)4, 588-610.

Lambright, K.T. (2009). Agency theory and beyond: Contracted providers' motivations to properly use service monitoring tools. Journal of Public Administration Research and Theory, 19, 207-227.

Mayhew, F. (2012). Aligning for impact: The influence of the funder-fundee relationship on evaluation utilization. Nonprofit Management and Leadership, 23(2), 193-217.

Murray, V. \& Tassie, W. (1994). Evaluating the effectiveness of nonprofit organizations. In R.D. Herman \& Associates (Eds.), The Jossey-Bass Handbook of Nonprofit Leadership and Management (pp. 303-324). San Francisco: Jossey-Bass.

Tassie, B., Murray, V., Cutt, J., \& Bragg, D. (1996). Rationality and politics: What really goes on when funders evaluate the performance of fundees? Nonprofit and Voluntary Sector Quarterly, 25, 347-363.

Tsui, A.S. (1990). A multiple-constituency model of effectiveness: An empirical examination at the human resource subunit level. Administrative Science Quarterly, 35, 458-483.

Van Slyke, D. M. (2007). Agents or stewards: Using theory to understand the governmentnonprofit social service contracting relationship. Journal of Public Administration Research and Theory, 17, 157-187.

Yin, Robert K. (2013). Case study research: Design and methods. $5^{\text {th }}$ ed. Thousand Oaks, CA: Sage Publications.

Zammuto, R.F. (1984). A comparison of multiple constituency models of organizational effectiveness. Academy of Management Review, 9, 606-616. 
Table 1. Forms of Performance Information Requested by Funders: Survey and Interview Data

\begin{tabular}{|l|l|l|}
\hline Type of Performance Information & $\begin{array}{l}\text { Count }(\%) \text { of } \\
\text { respondents to funder } \\
\text { survey }(\mathrm{n}=45)\end{array}$ & $\begin{array}{l}\text { Count (\%) funder } \\
\text { interviews (n=20) }\end{array}$ \\
\hline Outcome measurement & $40(89 \%)$ & $16(80 \%)$ \\
\hline Satisfaction surveys & $18(40 \%)$ & $2(10 \%)$ \\
\hline Expenditure reports & $42(93 \%)$ & $14(70 \%)$ \\
\hline Information on outputs & $32(71 \%)$ & $15(75 \%)$ \\
\hline
\end{tabular}

Table 2. Reasons for Collecting Performance Information: Survey and Interview Data

\begin{tabular}{|l|c|c|c|c|}
\hline \multicolumn{1}{|c|}{$\begin{array}{c}\text { Reasons for collecting } \\
\text { performance information }\end{array}$} & $\begin{array}{c}\text { Funder } \\
\text { count }(\%) \\
(\mathrm{n}=20)\end{array}$ & $\begin{array}{c}\text { Provider } \\
\text { count (\%) } \\
(\mathrm{n}=20)\end{array}$ & $\begin{array}{c}\text { Funder } \\
\text { mean } \\
\text { score } \\
(\mathrm{n}=45)\end{array}$ & $\begin{array}{c}\text { Provider } \\
\text { mean } \\
\text { score } \\
(\mathrm{n}=101)\end{array}$ \\
\hline Identify outcomes & $14(70 \%)$ & $7(35 \%)$ & 4.53 & 4.35 \\
\hline Verify work has been done & $11(55 \%)$ & $5(25 \%)$ & 4.49 & 4.21 \\
\hline Learn community needs & $10(50 \%)$ & $1(5 \%)$ & 4.24 & 3.99 \\
\hline Improve service & $2(10 \%)$ & $15(75 \%)$ & 4.02 & 4.5 \\
\hline Respond to client needs & $5(25 \%)$ & $10(50 \%)$ & 3.8 & 4.41 \\
\hline Empower clients & & & 3.31 & 4.07 \\
\hline Educate community about problems & & & 3.87 & 3.88 \\
\hline Meet funder requirements & $8(40 \%)$ & $8(40 \%)$ & & 3.83 \\
\hline Inform future funding decisions & $10(50 \%)$ & & & \\
\hline Learn provider needs for technical assistance & $5(25 \%)$ & & & \\
\hline Assess organizational capacity/sustainability & $4(20 \%)$ & & & \\
\hline Learn from programs' successes and failures & $2(10 \%)$ & & & \\
\hline Promote shared learning across agencies & $2(10 \%)$ & & & \\
\hline $\begin{array}{l}\text { Organization level or program-specific } \\
\text { planning }\end{array}$ & & $9(45 \%)$ & & \\
\hline
\end{tabular}

Note: Survey ratings measured on a five-point Likert scale: $1=$ strongly disagree, $2=$ disagree, $3=$ neither agree nor disagree, $4=$ agree, and 5=strongly agree. The second and third columns detail the number of interviews in which respondents identified a specific performance measurement purpose. We asked about the extent to which respondents were motivated to collect performance information to meet funder requirements on the provider survey only. 
Table 3. Reasons for Collecting Performance Information by Funder Type: Interview Data

\begin{tabular}{|l|c|c|c|c|}
\hline \multicolumn{1}{|c|}{ Performance Measurement Goals } & $\begin{array}{c}\text { Counties } \\
\text { count }(\%) \\
(\mathrm{n}=10)\end{array}$ & $\begin{array}{c}\text { Public } \\
\text { charities } \\
\text { count }(\%) \\
(\mathrm{n}=5)\end{array}$ & $\begin{array}{c}\text { Private } \\
\text { foundations } \\
\text { count (\%) } \\
(\mathrm{n}=5)\end{array}$ & $\begin{array}{c}\text { Total funder } \\
\text { count }(\%) \\
(\mathrm{n}=20)\end{array}$ \\
\hline Identify outcomes & $8(80 \%)$ & $4(80 \%)$ & $2(40 \%)$ & $14(70 \%)$ \\
\hline Verify work has been done & $3(30 \%)$ & $4(80 \%)$ & $4(80 \%)$ & $11(55 \%)$ \\
\hline Learn community needs & $6(60 \%)$ & $1(20 \%)$ & $3(60 \%)$ & $10(50 \%)$ \\
\hline Improve service & $0(0 \%)$ & $2(40 \%)$ & $0(0 \%)$ & $2(10 \%)$ \\
\hline Respond to client needs & $4(40 \%)$ & $1(20 \%)$ & $0(0 \%)$ & $5(25 \%)$ \\
\hline Meet funder requirements & $5(50 \%)$ & $3(60 \%)$ & $0(0 \%)$ & $8(40 \%)$ \\
\hline Inform future funding decisions & $6(60 \%)$ & $3(60 \%)$ & $1(20 \%)$ & $10(50 \%)$ \\
\hline $\begin{array}{l}\text { Learn provider needs for technical } \\
\text { assistance }\end{array}$ & $1(10 \%)$ & $2(40 \%)$ & $2(40 \%)$ & $5(25 \%)$ \\
\hline $\begin{array}{l}\text { Assess organizational } \\
\text { capacity/sustainability }\end{array}$ & $1(10 \%)$ & $2(40 \%)$ & $1(20 \%)$ & $4(20 \%)$ \\
\hline $\begin{array}{l}\text { Learn from programs' successes and } \\
\text { failures }\end{array}$ & $0(0 \%)$ & $2(40 \%)$ & $0(0 \%)$ & $2(10 \%)$ \\
\hline $\begin{array}{l}\text { Promote shared learning across } \\
\text { agencies }\end{array}$ & $0(0 \%)$ & $2(40 \%)$ & $0(0 \%)$ & $2(10 \%)$ \\
\hline
\end{tabular}

Note: The columns detail the number of interviewees who identified a specific performance measurement purpose.

Table 4. Performance Information Collected by Providers Not Required by Funders

\begin{tabular}{|l|c|}
\hline \multicolumn{1}{|c|}{ Type of Performance Information } & $\begin{array}{c}\% \text { of respondents to } \\
\text { provider survey } \\
\text { (n=98) }\end{array}$ \\
\hline Satisfaction surveys & $67 \%$ \\
\hline Quality assurance information & $57 \%$ \\
\hline Interviews with clients & $49 \%$ \\
\hline Expenditure reports & $46 \%$ \\
\hline Outcome measurements & $45 \%$ \\
\hline Goal accomplishments & $42 \%$ \\
\hline Outputs & $41 \%$ \\
\hline
\end{tabular}


Table 5. Summary of Funders' and Providers' Approaches to Performance Measurement

\begin{tabular}{|c|c|c|}
\hline & Funders & Providers \\
\hline $\begin{array}{l}\text { Commonly collected } \\
\text { performance data }\end{array}$ & $\begin{array}{l}\text { - } \text { Outcomes } \\
\text { - Expenditures } \\
\text { - Outputs }\end{array}$ & $\begin{array}{ll}\text { - } & \text { Outcomes } \\
\text { - } & \text { Expenditures } \\
\text { - } & \text { Outputs } \\
\text { - } & \text { Direct client feedback }\end{array}$ \\
\hline $\begin{array}{l}\text { Top reasons for collecting } \\
\text { performance information }\end{array}$ & $\begin{array}{l}\text { - To identify outcomes } \\
\text { - Verification of work }\end{array}$ & $\begin{array}{ll}\text { - } & \text { Service improvement } \\
\text { - } & \text { Respond to client } \\
\text { needs }\end{array}$ \\
\hline $\begin{array}{l}\text { Stakeholders identified as } \\
\text { critical in defining } \\
\text { performance }\end{array}$ & $\begin{array}{ll}\text { - } & \text { Individual donors } \\
\text { - } & \text { Institutional funders } \\
& \text { (state, federal } \\
\text { government) }\end{array}$ & $\begin{array}{l}\text { - Institutional funders } \\
\text { (public and private) } \\
\text { - Service recipients }\end{array}$ \\
\hline Views of collaboration & $\begin{array}{l}\text { - Many report } \\
\text { collaborative processes } \\
\text { - Many identify room } \\
\text { for improvement }\end{array}$ & $\begin{array}{l}\text { - Many report } \\
\text { collaborative processes } \\
\text { - Many identify room } \\
\text { for improvement }\end{array}$ \\
\hline
\end{tabular}

Table 6. Funder and Provider Performance Measurement Goals: Mann-Whitney Results

\begin{tabular}{|l|l|l|}
\hline & $\begin{array}{l}\text { Rating avg. } \\
\text { funders } \\
(\mathrm{n}=45)\end{array}$ & $\begin{array}{l}\text { Rating avg. } \\
\text { providers } \\
(\mathrm{n}=101)\end{array}$ \\
\hline Identify outcomes & 4.53 & 4.35 \\
\hline Verify work has been done & 4.49 & $4.21^{*}$ \\
\hline Learn community needs & 4.24 & 3.99 \\
\hline Improve service & 4.02 & $4.50^{* *}$ \\
\hline $\begin{array}{l}\text { Educate community about } \\
\text { problems }\end{array}$ & 3.87 & 3.88 \\
\hline Respond to client needs & 3.8 & $4.41^{* *}$ \\
\hline Empower clients & 3.31 & $4.07^{* *}$ \\
\hline
\end{tabular}

** Difference between funders and providers significant at .01 level, * Difference between funders and providers significant at .05 level 